\title{
Childhood Trauma in Schizophrenia: Current Findings and Research Perspectives
}

\author{
David Popovic ${ }^{1,2}$, Andrea Schmitt ${ }^{1,3 *}$, Lalit Kaurani4, Fanny Senner ${ }^{1,5}$, Sergi Papiol 1,5, \\ Berend Malchow ${ }^{6}$, Andre Fischer ${ }^{4}$, Thomas G. Schulze ${ }^{5}$, Nikolaos Koutsouleris ${ }^{1}$ and \\ Peter Falkai ${ }^{1}$

\begin{abstract}
1 Department of Psychiatry and Psychotherapy, University Hospital, Ludwig Maximilian University of Munich, Munich, Germany, ${ }^{2}$ International Max Planck Research School for Translational Psychiatry (IMPRS-TP), Munich, Germany, ${ }^{3}$ Laboratory of Neuroscience (LIM27), Institute of Psychiatry, University of São Paulo, São Paulo, Brazil, ${ }^{4}$ German Center of Neurodegenerative Diseases, University of Göttingen, Göttingen, Germany, ${ }^{5}$ Institute of Psychiatric Phenomics and Genomics, University Hospital, Ludwig Maximilian University of Munich, Munich, Germany, ${ }^{6}$ Department of Psychiatry and Psychotherapy, University Hospital of Jena, Jena, Germany
\end{abstract}

OPEN ACCESS

Edited by:

Susanne Walitza,

University of Zurich, Switzerland

Reviewed by:

Rajiv Radhakrishnan,

Yale University, United States

Alfredo Meneses,

Centro de Investigación y de Estudios

Avanzados (CINVESTAV), Mexico

${ }^{*}$ Correspondence:

Andrea Schmitt

Andrea.Schmitt@

med.uni-muenchen.de

Specialty section: This article was submitted to

Neuropharmacology, a section of the journal

Frontiers in Neuroscience

Received: 31 August 2018 Accepted: 07 March 2019

Published: 21 March 2019

Citation:

Popovic D, Schmitt A, Kaurani L,

Senner F, Papiol S, Malchow B, Fischer A, Schulze TG, Koutsouleris N and Falkai $P$ (2019) Childhood Trauma

in Schizophrenia: Current Findings

and Research Perspectives.

Front. Neurosci. 13:274.

doi: 10.3389/fnins.2019.00274
Schizophrenia is a severe neuropsychiatric disorder with persistence of symptoms throughout adult life in most of the affected patients. This unfavorable course is associated with multiple episodes and residual symptoms, mainly negative symptoms and cognitive deficits. The neural diathesis-stress model proposes that psychosocial stress acts on a pre-existing vulnerability and thus triggers the symptoms of schizophrenia. Childhood trauma is a severe form of stress that renders individuals more vulnerable to developing schizophrenia; neurobiological effects of such trauma on the endocrine system and epigenetic mechanisms are discussed. Childhood trauma is associated with impaired working memory, executive function, verbal learning, and attention in schizophrenia patients, including those at ultra-high risk to develop psychosis. In these patients, higher levels of childhood trauma were correlated with higher levels of attenuated positive symptoms, general symptoms, and depressive symptoms; lower levels of global functioning; and poorer cognitive performance in visual episodic memory end executive functions. In this review, we discuss effects of specific gene variants that interact with childhood trauma in patients with schizophrenia and describe new findings on the brain structural and functional level. Additive effects between childhood trauma and brain-derived neurotrophic factor methionine carriers on volume loss of the hippocampal subregions cornu ammonis (CA)4/dentate gyrus and CA2/3 have been reported in schizophrenia patients. A functional magnetic resonance imaging study showed that childhood trauma exposure resulted in aberrant function of parietal areas involved in working memory and of visual cortical areas involved in attention. In a theory of mind task reflecting social cognition, childhood trauma was associated with activation of the posterior cingulate gyrus, precuneus, and dorsomedial prefrontal cortex in patients with schizophrenia. In addition, decreased connectivity was shown between the posterior cingulate/precuneus region and the amygdala in patients 
with high levels of physical neglect and sexual abuse during childhood, suggesting that disturbances in specific brain networks underlie cognitive abilities. Finally, we discuss some of the questionnaires that are commonly used to assess childhood trauma and outline possibilities to use recent biostatistical methods, such as machine learning, to analyze the resulting datasets.

Keywords: neurodevelopment, childhood trauma, diagnostic tools, schizophrenia, machine learning

\section{INTRODUCTION}

Schizophrenia is a severe neuropsychiatric disorder that affects about 1\% of the population (Jablensky, 1995). It is particularly prevalent in young adults between 20 and 30 years of age and leads to disability in about half of the patients (Murray and Lopez, 1996). The disorder is among the leading cause of years lived with disability worldwide (Whiteford et al., 2013), and, among all mental illnesses, schizophrenia is associated with the highest socioeconomic costs (Gustavsson et al., 2011). This high disorder burden is due to the early onset of schizophrenia in late adolescence and early adulthood and the persistence of symptoms throughout adult life in over $90 \%$ of affected patients despite meeting remission criteria (Häfner and an der Heiden, 2007; Schennach et al., 2015). Symptom improvement has been measured as "therapeutic response," which was defined by, e.g., a $20 \%$ symptom reduction after 4 weeks of treatment (Kane et al., 1984). Subsequently, the term "remission" was introduced, requiring a simultaneous reduction of all diagnosis-specific core symptoms (positive and negative symptoms) to a level of "mild or less" on established questionnaires (Positive and Negative Syndrome Scale, Brief Psychiatric Rating Scale, Scale for the Assessment of Positive Symptoms, Scale for the Assessment of Negative Symptoms) for a minimum of 6 months (Andreasen et al., 2005). However, since only a small portion of schizophrenia patients can achieve this, the new definition of "recovery" was conceived, which takes into account not only a reduction of clinical symptoms, but also an improvement in occupational, social and adaptive functioning (Chan et al., 2018). However, only $20 \%$ of people with schizophrenia are able to work in the primary labor market, and only about $30 \%$ are able to maintain a stable relationship (Häfner and an der Heiden, 2007). The unfavorable disorder course is associated with multiple episodes and residual symptoms, mainly negative symptoms and cognitive deficits (McGrath et al., 2008). Cognitive deficits as a core feature of the disorder are present in domains such as episodic memory, executive function, social cognition, and attention (Green, 1996; Hoff et al., 2005). These deficits may lead to memory decline, social withdrawal, and ultimately impaired social and role functioning as measured by the Global Assessment of Functioning (GAF) scale (Green et al., 2015a). Several studies have operationalized the term "recovery" by using the GAF scale to investigate the long-term outcome and its relevant influencing factors in psychosis patients (Scott et al., 2013; Amminger et al., 2015; Koutsouleris et al., 2016; Jagannath et al., 2018; Lho et al., 2019). While childhood trauma has been repeatedly shown to negatively impact "recovery" among schizophrenia patients (Alameda et al., 2015, 2017; Trauelsen et al., 2016), some of these findings were only partially replicated (Trotta et al., 2016; Ajnakina et al., 2018), hereby leading to a rather heterogeneous body of evidence and consequently emphasizing the need for further research into the neurobiological underpinnings of this association.

\section{RISK FACTORS FOR SCHIZOPHRENIA AND THE NEURODEVELOPMENTAL HYPOTHESIS}

Twin studies found a heritability of about $60-80 \%$ for schizophrenia (Sullivan et al., 2003), and new genome-wide association studies (GWASs) revealed a total of 145 genetic risk loci, the single nucleotide polymorphisms (SNPs), each with only a weak effect (Pardinas et al., 2018). GWAS-based schizophrenia polygenic risk scores showed associations with social and cognitive impairments during early childhood, which were interpreted as being possible early manifestations of genetic liability (Riglin et al., 2017). In schizophrenia, however, about 8,300 SNPs have been estimated to contribute to a common risk of only $32 \%$ (Ripke et al., 2013), suggesting that-in addition to the genetic background-environmental factors may be the basis of pathophysiological processes (Manolio et al., 2009).

Schizophrenia has been regarded as a neurodevelopmental disorder in which defective genes and environmental factors interact and induce symptoms of the disorder. The neurodevelopmental hypothesis proposes that schizophrenia is related to adverse conditions, such as genetic background and environmental factors, which lead to abnormal brain development. Disorder onset and first symptoms occur in early adulthood, after synaptic pruning (Weinberger, 1996; Fatemi and Folsom, 2009). In the two-hit model, a neurodevelopmental disturbance during the perinatal period may lead to dysfunction of neuronal circuits and vulnerability to stress during vulnerable brain periods, and later psychosocial stress or drug abuse, for example, may then trigger the disorder (Schmitt et al., 2014). Today, researchers propose that several hits in the form of genetic and environmental risk factors may interact in a complex way during key periods of neurodevelopment and cumulate in the expression of the disorder state (Figure 1); these risk factors are hypothesized to be common across neuropsychiatric disorders such as schizophrenia, bipolar disorder, and major depression (Davis et al., 2016). The neural diathesis-stress model proposes that psychosocial stress acts upon a pre-existing vulnerability and triggers the symptoms of schizophrenia (Walker and Diforio, 1997). Specific stress factors have been 

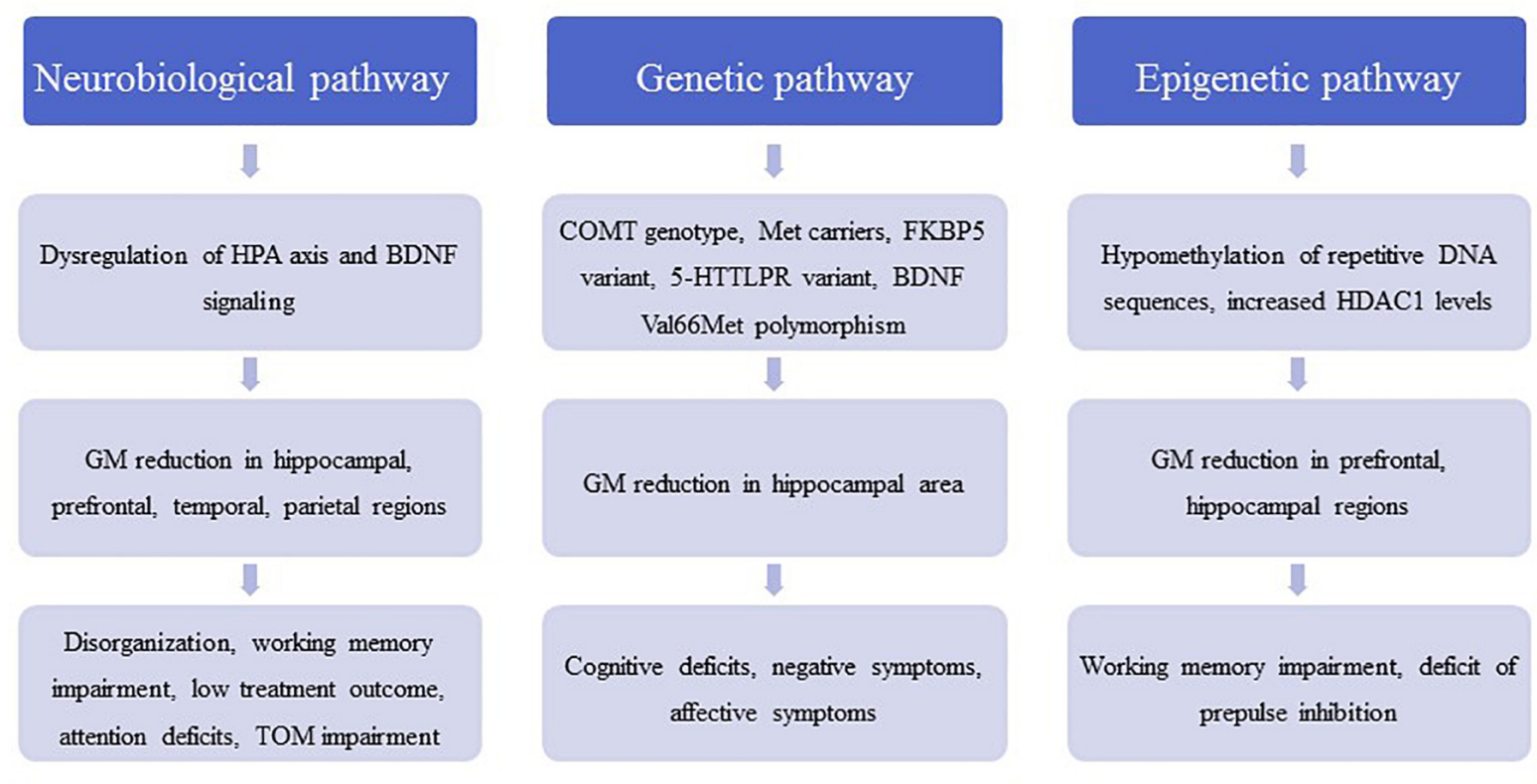

FIGURE 1 | The figure contains a general outline of the three main pathophysiological pathways between childhood trauma and schizophrenic symptoms. These pathways are meant to illustrate the pathological cascade ranging from molecular and (epi-) genetic abnormalities to neuroanatomical changes and eventually to the development of disorder-related symptoms. HPA, hypothalamic-pituitary-adrenal axis; BDNF, brain-derived neurotrophic factor; COMT,

catechol-O-methyltransferase; FKBP5, FK506 binding protein 5; 5-HTTLPR, serotonin-transporter-linked polymorphic region; HDAC1, histone deacetylase 1; TOM, theory of mind.

identified that trigger or worsen symptoms of the disorder, such as perceived uncontrollable threats to important goals and socio-evaluative threats (Jones and Fernyhough, 2007). In addition, schizophrenia patients are more emotionally reactive than non-psychiatric controls to stressors such as higher arousal and anxiety (Docherty et al., 2009).

\section{NEUROBIOLOGICAL EFFECTS OF STRESS}

Stress sensitization may play a role in schizophrenia by lowering the vulnerability threshold for the disorder. The neurobiological consequence of stress sensitization involves dysregulation of the hypothalamus-pituitary-adrenal (HPA) axis, which is the major stress neuroendocrine system of the body and is involved in the production of the stress hormone cortisol by the adrenal glands (Holtzman et al., 2013; Schmitt et al., 2014). A stressinduced activation of the HPA axis contributes to dopamine sensitization in mesolimbic areas and increases stress-induced striatal dopamine release (van Winkel et al., 2008). These effects are important because increased dopamine neurotransmission with overstimulation of the $\mathrm{D}_{2}$ receptors in several brain regions has been hypothesized in the pathophysiology of schizophrenia, a hypothesis that is supported by the antipsychotic effects of dopamine receptor antagonists (Falkai et al., 2011).

In animal models, acute or chronic stress decreased brainderived neurotrophic factor (BDNF) levels in the hippocampus, which is involved in synaptogenesis (Neto et al., 2011). In accordance with these findings, stress was found to reduce hippocampal dendrites (Magarinos et al., 2011). Additionally, application of glucocorticoids reduced hippocampal BDNF levels, mimicking the stress reaction (Neto et al., 2011). Animal models have shown that chronic stress or repeated administration of glucocorticoids results in degeneration of hippocampal neurons, with decreased soma size and atrophy of dendrites (Sapolsky et al., 1990; Watanabe et al., 1992). This stress-induced glucocorticoid neurotoxicity (Arango et al., 2001; Frodl and O'Keane, 2013) may contribute to a volume loss in vulnerable brain regions such as the hippocampus; hippocampal volume reduction has been reported for schizophrenia even in early disorder stages (Adriano et al., 2012). Moreover, elevated glucocorticoids can suppress myelination and may affect calcium channels (Damsted et al., 2011). Both mechanisms are related to the pathophysiology of schizophrenia and result in impaired macro- and microconnectivity (Berger and Bartsch, 2014; Cassoli et al., 2015).

In rodents, juvenile social isolation and maternal separation are models of childhood stress, and these animal models have shown lasting effects on the HPA axis along with deficits in hippocampus-dependent learning and memory (Bremne and Vermetten, 2001). The mouse model of juvenile social isolation builds on social isolation immediately after weaning: social isolation leads to schizophrenia-related behavior, such as deficits in prepulse inhibition of the acoustic startle response (PPI) and working memory and decreased social exploration. Furthermore, deficits in oligodendrocyte morphology, reduced myelin thickness, 
and decreased myelin basic protein and myelin-associated glycoprotein expression have been detected in brain regions (Varty et al., 2006; Makinodan et al., 2012) and resemble the deficit of myelination and oligodendrocytes in schizophrenia (Cassoli et al., 2015). Importantly, in contrast with the effects of adult social isolation this early-induced phenotype cannot be rescued by later social re-integration (Makinodan et al., 2012), implicating impaired recovery, such as in schizophrenia (Table 1).

\section{STRESS RESPONSE IN PATIENTS WITH SCHIZOPHRENIA AND INDIVIDUALS AT ULTRA-HIGH RISK OF DEVELOPING PSYCHOSIS}

An increased release of glucocorticoids has been proposed to play a role in the pathophysiology of schizophrenia (Corcoran et al., 2003), and the stress-diathesis model proposes that schizophrenia is associated with elevated baseline and challenge-induced HPA activity (Walker et al., 2008). In addition, cortisol treatment can induce psychotic symptoms (Walker et al., 2008). This model is supported by reports of increased levels of blood cortisol (Ryan et al., 2004) and a blunted cortisol response to stress (Mondelli et al., 2010); the latter was suggested to reflect impaired responsiveness of a desensitized system. Indeed, a meta-analysis on stress-moderating effects of baseline cortisol levels revealed that schizophrenia patients have lower cortisol levels than controls during anticipation of social stress and after exposure to it (Ciufolini et al., 2014). A reduced ability of these patients to appropriately contextualize past experiences has been hypothesized to underlie the missing cortisol response in these experiments (Ciufolini et al., 2014). A blunted cortisol

TABLE 1 | Major animal models of early life stress corresponding to childhood trauma.

\begin{tabular}{|c|c|c|c|}
\hline Study & $\begin{array}{l}\text { Stress } \\
\text { paradigm }\end{array}$ & Effects on behavior & $\begin{array}{l}\text { Effects on brain } \\
\text { biology }\end{array}$ \\
\hline $\begin{array}{l}\text { Bahari- } \\
\text { Javan } \\
\text { et al., } 2017\end{array}$ & $\begin{array}{l}\text { Maternal } \\
\text { separation }\end{array}$ & $\begin{array}{l}\text { Short-term memory } \downarrow \\
\text { Prepulse inhibition } \downarrow \\
\text { Novel object } \\
\text { recognition learning } \downarrow \\
\text { HDAC inhibitor MS-274 } \\
\text { rescues ELS induced } \\
\text { impairment in PPI and } \\
\text { improves novel object } \\
\text { recognition learning }\end{array}$ & $\begin{array}{l}\text { Hdac1 mRNA } \uparrow \\
\text { HDAC1 protein } \uparrow \\
\text { DNA-methylation of the } \\
\text { Hdac1 gene at the } \\
\text { glucocorticoid receptor } \\
\text { (GR-) binding site } \downarrow\end{array}$ \\
\hline $\begin{array}{l}\text { Makinodan } \\
\text { et al., } 2012\end{array}$ & $\begin{array}{l}\text { Juvenile } \\
\text { social } \\
\text { isolation }\end{array}$ & $\begin{array}{l}\text { Social interaction } \downarrow \\
\text { Working memory } \downarrow \\
\text { No reversed behavior } \\
\text { by reintroduction to a } \\
\text { social environment }\end{array}$ & $\begin{array}{l}\text { Oligodendrocytes with } \\
\text { simpler morphology } \\
\text { Myelin Basic Protein } \\
\text { mRNA } \downarrow \\
\text { Myelin Associated } \\
\text { Glycoprotein mRNA } \downarrow \\
\text { Myelin thickness } \downarrow \\
\text { Neuregulin1 type III } \\
\text { mRNA } \downarrow\end{array}$ \\
\hline $\begin{array}{l}\text { Varty et al., } \\
2006\end{array}$ & $\begin{array}{l}\text { Isolation } \\
\text { rearing }\end{array}$ & Prepulse inhibition $\downarrow$ & \\
\hline
\end{tabular}

stress reactivity in schizophrenia patients was again reported in a more recent meta-analysis by Zorn et al. (2017), who also pointed toward a possible publication bias as well as an overall small number of studies with properly standardized cortisol protocols as limiting factors for the interpretation of these findings. Moreover, treatment with antipsychotics may have influenced the results (Walker et al., 2008). However, the HPA axis response was also impaired in medication-naïve patients with first-episode schizophrenia, i.e., the cortisol response was flattened, indicating impairments in stress processing (van Venrooij et al., 2012).

According to the neurodevelopmental hypothesis, prodromal and psychotic symptoms occur for the first time in adolescence. In adolescents at ultra-high risk of psychosis (UHR), increased resting cortisol levels have been reported and associated with higher rates of critical statements from relatives and negative self-concept (Carol and Mittal, 2015), indicating that a dysfunction of the HPA axis is related to environmental characteristics. The cortisol level after awakening, which reflects HPA regulation, was also increased in this patient group compared with healthy controls (Nordholm et al., 2018). Additionally, in UHR adolescents a reduced stress responsivity of the HPA axis was correlated with smaller gray matter volumes of the hippocampus and prefrontal, temporal, and parietal cortices, which may represent the neural components in the stress vulnerability model (Valli et al., 2016) (Figure 1). Interestingly, those individuals who subsequently developed psychosis showed a significant blunting of the HPA stress response (Valli et al., 2016).

\section{EFFECTS OF CHILDHOOD MALTREATMENT ON EPIGENETIC PROCESSES}

In addition to effects on the hormone system, environmental factors, such as childhood trauma, may contribute to genomeenvironment interactions; these interactions are mediated by epigenetic processes, such as DNA methylation and histone modifications (Fischer, 2014). Hypomethylation of DNA repetitive sequences has been detected in first-episode schizophrenia patients with a history of childhood trauma (Misiak et al., 2015). Inhibitors of histone deacetylases (HDAC) have been suggested to improve cognitive function and ameliorate disorder pathogenesis in neuropsychiatric disorders such as schizophrenia (Nestler et al., 2016). In schizophrenia patients, we found that the experience of childhood trauma was related to increased HDAC1 levels in blood samples (Bahari-Javan et al., 2017). This corresponds with recent findings that HDAC1 levels are increased in the prefrontal cortex and hippocampus of patients with schizophrenia (Benes et al., 2007; Sharma et al., 2008; Bahari-Javan et al., 2017) (Figure 1). Interestingly, in mice with early life stress as a model of childhood trauma HDAC1 expression is increased in the prefrontal cortex and hippocampus, and these mice display schizophrenia-like behavioral phenotypes, such as deficits in PPI, working memory, and synaptic plasticity (Bahari-Javan et al., 2017) (Table 1). 
The effects of childhood trauma on epigenetic mechanisms and the relationship with cognition and disorder symptoms should be investigated in more detail in larger studies in schizophrenia patients.

\section{CHILDHOOD TRAUMA IN SCHIZOPHRENIA: EVIDENCE FROM HUMAN STUDIES}

Childhood trauma can be assumed to be a severe form of stress that renders individuals more vulnerable to developing schizophrenia. In a meta-analysis of 18 case-control studies (including 2048 patients with psychosis and 1856 nonpsychiatric controls), 10 prospective studies (including 41,803 participants), and 8 population-based cross-sectional studies (35,546 participants), Varese et al. (2012) found that adverse experiences in childhood significantly increased the risk to develop psychosis and schizophrenia. The group showed a significant association between childhood adversity, including trauma, and psychosis: the odds ratio was between 2.72 and 2.99 , indicating a strong association between childhood adversity and psychosis, including schizophrenia. Epidemiological studies show that exposure to early stress in the form of abuse and neglect in childhood increases the risk to later develop schizophrenia (Bonoldi et al., 2013). In schizophrenia patients, the most frequent subtype of trauma was emotional neglect, but rates of physical abuse and physical neglect were also significantly increased (Larsson et al., 2013). Childhood abuse and neglect are known to have a negative influence on cognition in patients with schizophrenia and bipolar disorder (Shannon et al., 2011). In first-episode schizophrenia patients, exposure to childhood neglect was a predictor for impairment in social cognition and poorer verbal learning, whereas abuse was not (Kilian et al., 2017). A study in Chinese patients with schizophrenia reported that physical neglect was negatively correlated with delayed memory and attention and with the total cognition score (Li et al., 2017). A large study assessed 406 patients with schizophrenia spectrum disorders with the Childhood Trauma Questionnaire and found that physical abuse, sexual abuse, and physical neglect were significantly associated with reduced scores in working memory, executive function, and verbal tasks (Aas et al., 2012b). In another study, metacognitive capacity was lower in patients with childhood emotional abuse (Aydin et al., 2016). Female patients who reported childhood physical abuse had more psychotic and depressive symptoms than both women without this history and men with or without a trauma history (Kelly et al., 2016).

UHR individuals more frequently had a history of childhood trauma, such as emotional and sexual abuse as well as emotional and physical neglect, while emotional neglect in particular was associated with paranoid symptoms (Appiah-Kusi et al., 2017). Even in UHR individuals, a history of childhood maltreatment predicted poorer functioning at follow-up in both those who had transitioned to psychosis and those who had not (Yung et al., 2015). Childhood trauma did not predict transition to psychosis, but after a 2-year follow-up UHR individuals with higher levels of childhood trauma had higher levels of attenuated positive symptoms, general symptoms, and depressive symptoms and lower levels of global functioning (Kraan et al., 2015). In children born to parents with major psychoses, those who were exposed to abuse or neglect had lower IQ and GAF scores and displayed poorer cognitive performance in visual episodic memory end executive functions (Berthelot et al., 2015).

\section{INTERACTION OF CHILDHOOD TRAUMA WITH GENETIC FACTORS}

Gene-environment interactions have been suggested to play a role in the pathophysiology of schizophrenia (Figure 1). In 429 patients with schizophrenia or schizoaffective disorder, the catechol-O-methyltransferase (COMT) genotype moderated the effects of childhood trauma on cognition and symptoms in methionine (met) carriers with a history of childhood physical abuse and more severe positive symptoms; Met carriers with a history of emotional neglect had more severe negative symptoms (Green et al., 2014). In another study, a variant of the FK506 binding protein 5 (FKBP5) gene interacted with childhood trauma and affected attention in both schizophrenia patients and healthy controls (Green et al., 2015b). In patients with schizophrenia and affective disorders, an interaction between a variant in the serotonin transporter gene 5-HTTLPR and childhood trauma was observed in the California Verbal Learning Test (Aas et al., 2012a). A variant of BDNF Val66Met polymorphism was shown to moderate the impact of childhood adversity on later expression of affective symptoms in schizophrenia patients (Sahu et al., 2016). In 249 patients with schizophrenia spectrum disorder, carriers of the met allele of the BDNF gene exposed to high levels of childhood physical and emotional abuse demonstrated poorer cognitive functioning than monozygotic valine carriers. Moreover, Met carriers exposed to childhood sexual abuse showed reduced right hippocampus volume (Aas et al., 2013), suggesting negative effects on neuroplasticity in the brain. On an epigenetic level, a recent review concluded that childhood trauma was associated with global DNA hypomethylation and reduced BDNF gene-expression in first-episode psychosis subjects (Tomassi and Tosato, 2017). However, the literature on gene-environment relationship in the etiology of psychosis is rather heterogeneous as the results from candidate gene studies could quite frequently not be replicated (Zwicker et al., 2018). Thus, epidemiological studies investigating the interplay between familial and environmental factors in the development of psychosis within large cohorts are another valuable resource for further insight. Using these epidemiological approaches, it was found that environmental risk factors, such as childhood adversity, and a family history of affective and psychotic disorders additively impact the psychosis risk across a multidimensional spectrum of positive, negative, cognitive and affective symptoms (Binbay et al., 2012; Pries et al., 2018; Radhakrishnan et al., 2018). Moreover, studies repeatedly showed that childhood adversity and familial liability increased the risk predominantly for positive symptoms of psychosis, such as delusions and hallucinations, as 
well as affective symptoms (Jeppesen et al., 2015; Smeets et al., 2015; Veling et al., 2016). Therefore, the connection between childhood trauma, familial liability and the onset of psychosis is increasingly being labeled as one of the key mechanisms of the proposed "affective pathway" to psychosis (Isvoranu et al., 2017).

\section{BRAIN STRUCTURAL AND FUNCTIONAL CORRELATES OF CHILDHOOD TRAUMA}

Emotional neglect in patients with schizophrenia was negatively associated with total gray matter volume and specifically with the density and volume of the dorsolateral prefrontal cortex, which in turn predicted disorganization (Cancel et al., 2015). Interestingly, additive effects of childhood trauma and being a BDNF met carrier on volume loss in the hippocampal subregions cornu ammonis (CA)4/dentate gyrus and CA2/3 have been reported in schizophrenia (Aas et al., 2014). Childhood maltreatment has been associated with reduced hippocampal volume as well as amygdala hyperreactivity and was shown to predict poor treatment outcome (Teicher and Samson, 2013). A functional magnetic resonance imaging study showed that childhood trauma exposure resulted in aberrant function of parietal areas involved in working memory and of visual cortical areas involved in attention. On the basis of these data, the authors hypothesized that childhood trauma in psychosis contributes to alterations in attention during performance of working memory tasks (Quide et al., 2017a). During a theory-of-mind task that reflected social cognition, childhood trauma was associated with activation of the posterior cingulate gyrus, precuneus, and dorsomedial prefrontal cortex in patients with schizophrenia (Quide et al., 2017b). In addition, decreased connectivity between the posterior cingulate/precuneus region and the amygdala was shown in patients with high levels of physical neglect and sexual abuse during childhood (Cancel et al., 2017) (Figure 1). Finally, an fMRI study showed an increased brain response to emotionally negative faces compared with the response to positive faces in patients with psychosis and high childhood trauma, as assessed by the Childhood Trauma questionnaire (Aas et al., 2017). Overall, findings from MRI, genetic, and largescale gene expression and epigenetic studies often were not reproducible and need to be replicated in larger samples before final conclusions can be drawn.

\section{LACK OF SPECIFICITY OF FINDINGS FOR SCHIZOPHRENIA}

It must be noted that effects of childhood trauma are not specific for schizophrenia. In childhood-maltreatment related post-traumatic stress disorder (PTSD), a recent meta-analysis clearly showed bilateral reduction of hippocampal and amygdala volumes in the PTSD group compared to healthy controls (Ahmed-Leitao et al., 2016). In addition, cognitive deficits in different domains such as general intelligence, language, information processing, learning and memory and executive skills have been observed in trauma-exposed children with PTSD compared to controls. Trauma-exposed children with PTSD had poorer general intelligence and visuospatial skills compared with trauma-exposed children who did not develop PTSD (Malarbi et al., 2017). Dysfunction of the HPA axis in PTSD has been reported, particularly hypersensitivity of the glucocorticoid receptor (GR). Single-nucleotide polymorphisms (SNPs) in the GR and FKBP5 gene were associated with PTSD risk and the FKBP5 gene SNP interacted with childhood adversity to moderate PTSD risk (Binder et al., 2008; Castro-Vale et al., 2016). Other neurochemical markers for PTSD include neurotrophic factors such as BDNF (Bandelow et al., 2017). Regarding epigenetic factors, DNA methylation is so far the best studied in PTSD and could be responsible for long-lasting effects of geneenvironmental interactions (Rampp et al., 2014). Furthermore, effects of parental trauma could be transmitted to the next generation by epigenetic marks (Ramo-Fernandez et al., 2015).

A meta-analysis showed that childhood psychological abuse and neglect were strongly associated with depression (Infurna et al., 2016). Other factors of childhood maltreatment related to adult depression were emotional abuse, sexual abuse, domestic violence and physical abuse (Mandelli et al., 2015). Regarding genetic factors, the corticotropin-releasing hormone receptor 1 (CRHR1) gene may moderate the effects of childhood trauma on depression (Heim et al., 2009; Ressler et al., 2010). BDNF gene methylation level was correlated with depression (Chen et al., 2017).

\section{TOOLS TO ASSESS CHILDHOOD TRAUMA}

In the field of childhood trauma research, it is not uncommon to investigate early stress by clinically assessing whether some form of maltreatment took place in the individual's childhood without applying standardized trauma or maltreatment questionnaires (Choi and Sikkema, 2016; Green et al., 2017). However, in the context of clinical studies and to further both the validity and the reliability of the observed effects in childhood trauma studies, standardized instruments should be used. Below, we present a representative selection of the most commonly used questionnaires because it would be beyond the scope of this article to include all the available ones.

Overall, questionnaires on childhood trauma can be categorized into instruments to diagnose PTSD and more specialized assessment tools, whose goal is to assess childhood maltreatment in depth rather than to validate a DSM or ICD diagnosis. A vast number of PTSD-specific questionnaires are available, but we will give an overview of three structured interviews and one self-report measure. The Structured Clinical Interview for DSM-IV (SCID) and the Composite International Diagnostic Interview (CIDI) are structured interviews that cover the entire spectrum of mental disorders and can be applied by both trained professionals and trained lay interviewers. Both interviews have a specific section on PTSD, are frequently used in epidemiological studies and can be used to validate a suspected diagnosis of PTSD (Kessler et al., 2007; Stein et al., 2014; Guina et al., 2016). Another instrument that has also been extensively 
reviewed and is regarded by some as the gold standard in diagnosing PTSD is the Clinician-Administered PTSD Scale (CAPS). The CAPS is a 30 -item structured interview that should ideally be administered by clinicians and clinical researchers with a working knowledge of PTSD (Weathers et al., 2001, 2018). In addition to these structured interviews, the PTSD Checklist for DSM-5 (PCL-5), a 20-item self-report measure that assesses the 20 DSM-5 symptoms of PTSD, can be used to solidify a PTSD diagnosis (Franklin et al., 2018).

Besides these PTSD-specific diagnostic instruments, a large group of questionnaires focuses on distinct types of childhood maltreatment that do not automatically have to fulfill the PTSD criteria. Childhood maltreatment is usually assessed along the domains of abuse (physical, sexual, emotional/psychological) and neglect (emotional/psychological, physical) (Hovdestad et al., 2015). The most commonly used childhood maltreatment selfreports and semi-structured interviews are described here. The Childhood Trauma Questionnaire (CTQ, Bernstein et al., 1997 ) is one of the most frequently used self-reports in the current literature (Viola et al., 2016). It has a total of 28 items and measures the above mentioned five types of maltreatment, i.e., emotional, physical, and sexual abuse, and emotional and physical neglect. It also includes a three-item minimization/denial scale to assess the potential underreporting of maltreatment. Another common self-report tool is the Personal Safety Questionnaire (PSQ), which is based on the Conflicts Tactics Scales (Straus and Douglas, 2004). The PSQ queries the occurrence of specific incidents and mainly focuses on physical or sexual abuse; it can be used to sequentially assess incidents that occur in childhood, adolescence, or adulthood. This feature allows researchers to examine both the type (physical or sexual) and timing of abuse over life periods (Rich-Edwards et al., 2011). A questionnaire that specifically focuses on sexual abuse in childhood is the Child Sexual Assaults Scale (CSAS, Koss et al., 1987). This instrument assesses sexual abuse along five subscales: demographic variables subscale, PTSD symptom subscale, center for epidemiologic studies depression subscale, traumatic events questionnaire, and childhood sexual experiences subscale (Yampolsky et al., 2010). An advantage of the CSAS is that it not only assesses possible traumatizing sexual events, but it also checks for PTSD and affective symptoms, therefore mirroring the complex nature of this kind of childhood trauma. Because large multi-center studies have become more important in today's psychiatry, the Early Trauma Inventory Self Report (ETI-SR) represents a powerful assessment tool that has the advantage of being validated many languages (German, French,

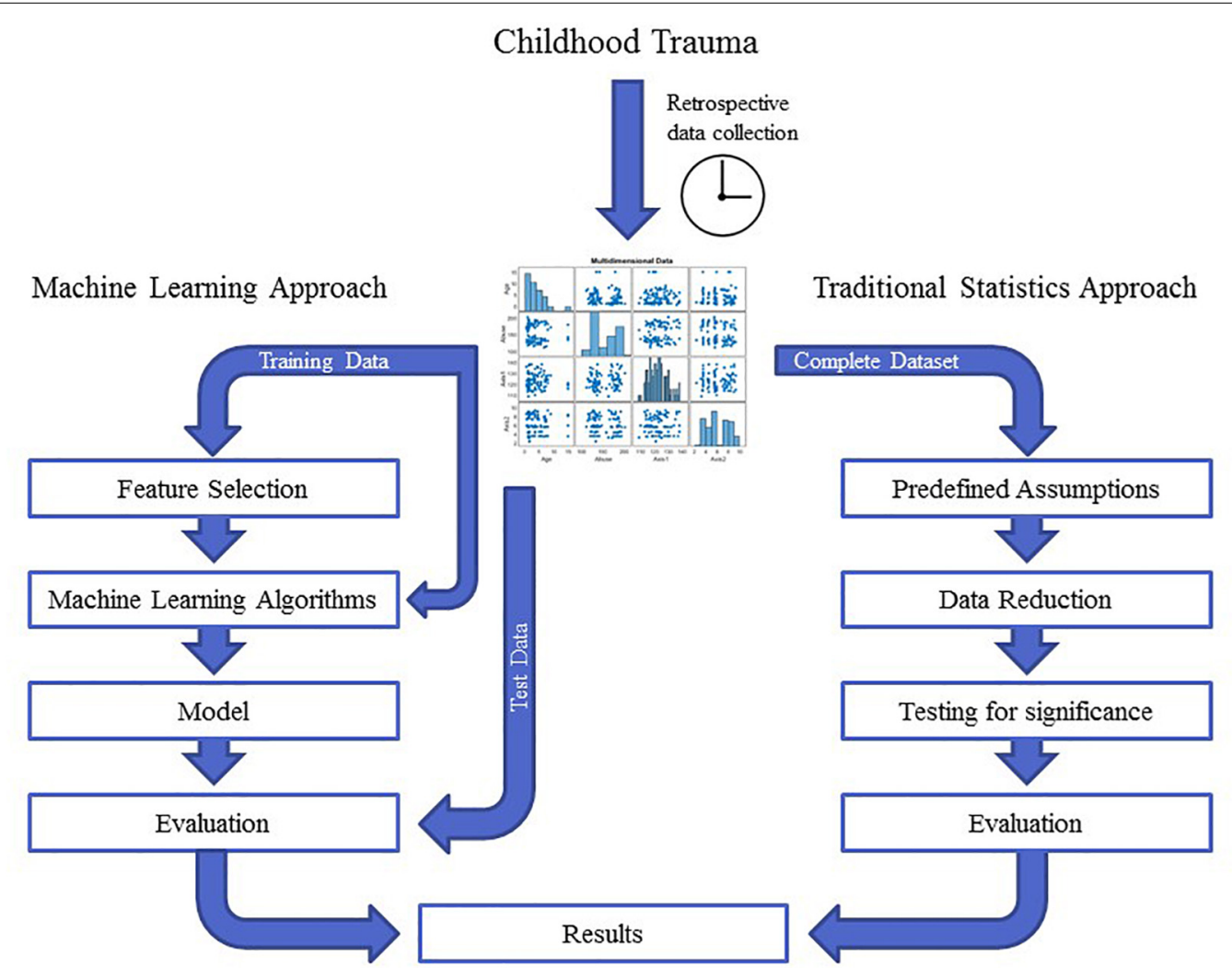

FIGURE 2 | The graph depicts the different workflows in traditional statistics compared with machine learning approaches. In traditional statistics, one approaches a dataset with predefined assumptions, reduces the entire dataset according to those assumptions and then tests a certain hypothesis for significance. In contrast, unbiased machine learning approaches split the dataset into training and test data and let an algorithm learn from the training data in an unbiased and hypothesis-free manner. The evaluation of the analysis then depends on how well the model performs when applied to the test data. These two approaches can yield quite different results. 
Chinese, Spanish, Portuguese, Plaza et al., 2012). The ETI-SR is a 56-item inventory that assesses the presence of childhood trauma with a series of "yes or no" questions and includes specific items for physical ( 9 items), emotional (7 items), and sexual abuse (15 items) and general trauma (31 items). It also assesses the frequency of trauma, age at trauma, perpetrator, and other variables before age 18 (Bremner et al., 2007; Plaza et al., 2011). The Traumatic Life Events Questionnaire (TLEQ) can be a viable alternative if a broader perspective on possible traumatic or adverse life events is desired. This tool assesses exposure to 16 types of potentially traumatic events, including natural disasters, exposure to warfare, unexpected death of a loved one, severe physical assault, different forms of sexual abuse, and experiences of stalking, and also accounts for the frequency and severity of the named traumatic experiences (Kubany et al., 2000). A rather brief self-report questionnaire is the Adverse Childhood Experiences (ACE) questionnaire (Felitti et al., 1998). In a total of 17 questions, this questionnaire assesses childhood abuse within the domains of psychological, physical, and sexual abuse. Additionally, it sets itself apart from many other selfreports because it also includes four categories of childhood exposure to household dysfunction, i.e., substance abuse, mental illness, violent treatment of mother or stepmother, and criminal behavior in the household.

With regards to semi-structured interviews, two more questionnaires are of interest because they both have specific advantages and can be useful in clinical studies: The Early Trauma Inventory and the Children's Life Events Scale (CLES).
The former instrument is a semi-structured interview that assesses four domains of traumatic experiences (physical, emotional, and sexual abuse and general traumatic experience) and then addresses the most serious trauma in an additional question (Bremner et al., 2000). This additional question can be very useful in clinical settings because of the potential need for an extended conversation about the most burdensome issue. The CLES, which is an expansion of The Source of Stress Inventory (Chandler, 1981), is a checklist composed of 50 moderate-tomajor stressful childhood events that covers categories such as negative emotional feedback, family deaths, maltreatment, failure in school, and family dysfunction (Crossfield et al., 2002; Grandin et al., 2007).

When selecting a questionnaire, equally important to the frequency of use is the analysis of the resulting dataset. Therefore, in the next section we critically discuss current analysis methods and give an outlook on advanced mathematical analysis methods.

\section{NOVEL APPROACHES FOR ASSESSING AND ANALYZING CHILDHOOD MALTREATMENT}

Childhood trauma poses several challenges when it comes to data integration and data analysis, mainly with regards to the temporal resolution and the reciprocity and interdependency of the observed phenotypes. The temporal problem arises because most adverse events, which presumably occurred

\begin{tabular}{|c|c|c|}
\hline \multicolumn{3}{|l|}{ Supervised learning } \\
\hline Category & Algorithms & Purpose \\
\hline $\begin{array}{l}\text { Classification and } \\
\text { regression trees }\end{array}$ & $\begin{array}{l}\text { Boosted trees, bootstrap aggregated trees (including } \\
\text { random forests), rotation forests }\end{array}$ & Classification, Regression \\
\hline Regression analysis & Linear/logistic regression models & Regression \\
\hline Naive Bayes (NB) & Gaussian NB, multinomial NB, Bernoulli NB & Classification \\
\hline $\begin{array}{l}\text { Artificial Neural } \\
\text { Networks (ANN) }\end{array}$ & $\begin{array}{l}\text { Feedforward NN (including Convolutional NN), } \\
\text { Regulatory Feedback NN, Radial Basis Function } \\
\text { NN, Recurrent NN, Modular NN }\end{array}$ & Classification, Regression \\
\hline Vector Machines & $\begin{array}{l}\text { Relevance Vector Machines (RVM), } \\
\text { Support Vector Machines (SVM) }\end{array}$ & Classification, Regression \\
\hline \multicolumn{3}{|c|}{ Unsupervised learning } \\
\hline Category & Algorithms & Purpose \\
\hline Clustering & $\begin{array}{l}\text { Hierarchical clustering, k-means, (Non-/Bayesian) } \\
\text { mixture models, DBSCAN, OPTICS algorithm }\end{array}$ & Clustering, Classification \\
\hline ANN & $\begin{array}{l}\text { Autoencoders, Deep Belief Networks, Hebbian } \\
\text { Learning, Generative Adversarial Networks, self- } \\
\text { organizing maps }\end{array}$ & Clustering, Classification \\
\hline $\begin{array}{l}\text { Latent variable } \\
\text { models }\end{array}$ & $\begin{array}{l}\text { Expectation-maximization algorithm, PCA, ICA, } \\
\text { Non-negative Matrix Factorization, Singular Value } \\
\text { Decomposition (including PLS) }\end{array}$ & $\begin{array}{l}\text { Dimensionality Reduction, } \\
\text { Clustering, Classification }\end{array}$ \\
\hline
\end{tabular}

FIGURE 3 | The figure depicts the most widely used supervised and unsupervised learning algorithms. NN, neural network; DBSCAN, Density-Based Spatial Clustering of Applications with Noise; OPTICS, ordering points to identify the clustering structure; PCA, principal component analysis; ICA, independent component analysis; PLS, partial least squares. 
in childhood, can only be assessed retrospectively and are therefore prone to a certain recollection bias (MacDonald et al., 2015). Furthermore, the sequence in which adverse events in childhood were experienced and psychiatric symptoms developed is often unclear. Another issue lies in the reductionist steps that most studies take during "preprocessing" of the data on adverse experiences or events. In the first step, the data are categorized into specific overarching domains, such as physical or emotional abuse (Morgan and Fisher, 2007), which removes a great amount of the detailed information given by the individual. The next quite common reductionist step is to build sum scores for these domains or, in some cases, a total score for all domains (Hovdestad et al., 2015). In this second step, information given by patients is summarized into nominal or ordinal categories, for example "childhood trauma present" versus "childhood trauma absent" or "high childhood trauma," "medium childhood trauma," and "low childhood trauma" (Daruy-Filho et al., 2011; Agnew-Blais and Danese, 2016). This step removes a great amount of variance and heterogeneity within the dataset that could be important for future analyses. Overall, these preprocessing steps take the interdependency and reciprocity of these adversary factors and their association with the observed psychopathology out of the equation. The possible interactive effects between various kinds of adverse experiences, psychopathological symptoms, and organic features (i.e., structural and functional MRI, DNA variants, gene expression, or epigenetic mechanisms) of the affected individual are largely removed. Thus, most current studies in the field of childhood trauma research are trying to investigate a highly dynamic phenomenon, in which various risk and protective factors interact with each other and produce complex clinical and organic phenotypes, with simplified models that use ordinal and nominal grouping and univariate statistics (Figure 2). At the same time, age and sex are mostly controlled for, even though age- and sex-specific effects are found in various psychiatric disorders (Cascio et al., 2012; Gur and Gur, 2016). Based on these methodological issues, the potential advantage of using unbiased and explorative machine learning and multivariate analysis techniques becomes evident (Dwyer et al., 2018b; Jollans and Whelan, 2018). While supervised learning algorithms such as neural networks, tree-based algorithms and vector machines can deliver insights into psychiatric disorders through classification and regression of labeled training data (Bzdok et al., 2018), unsupervised learning algorithms are able to complement this by uncovering latent structures within an unlabeled training dataset (Figure 3). Hence, latent variable models based on factor analysis or singular value decomposition (i.e., principal component analysis, nonnegative matrix factorization, partial least squares) might be used to explore associative effects between variables of interest (Jessen et al., 2018; Stein-O’Brien et al., 2018). In this context, these associative effects could then be used to further explore causal links between different kinds of childhood adversity, psychopathology, and organic features, e.g., MRI images or DNA expression profiles (Krakauer et al., 2017). Other unsupervised techniques like hierarchical clustering or self-organizing maps could be employed to find mathematically sound clusters of adverse childhood effects or certain phenotypical or organic patterns of childhood trauma, that would be lost if one kept to the overly restrictive approach of using DMS diagnoses or categorical/nominal grouping of childhood trauma loading (Dwyer et al., 2018a). Another interesting topic for analysis with multivariate tools is the timeline of each individual, which is defined by specific childhood trauma experiences and onset and development of certain symptoms.

The effect of childhood trauma on psychopathology and organic variables, such as brain structure and DNA variants (see above), cannot be reduced to a static observation, and we need to consider longitudinal data, the course of disorder, and the biography of each individual. Therefore, mixture models involving (Hidden) Markov Models, Directed Graphical Models, and Bayesian Networks, would help to model, predict and consequently explain the connection and evolution of childhood trauma, psychopathology, and, if desired, its organic correlates (Orphanou et al., 2014; Ryali et al., 2016; Seltman et al., 2016). Some of these approaches have already been undertaken in the field of PTSD research (GalatzerLevy et al., 2014; Karstoft et al., 2015); however, to our knowledge in the field of childhood trauma and psychosis research no studies have yet been published on machine learning techniques (Figure 1). Therefore, this still unexplored field of unbiased, data-driven childhood trauma research has exciting potential and should be one of the priorities for future research.

\section{AUTHOR CONTRIBUTIONS}

PF, BM, AS, and DP designed this manuscript. DP, AS, LK, FS, $\mathrm{SP}, \mathrm{BM}, \mathrm{AF}, \mathrm{TS}, \mathrm{NK}$, and PF managed the literature searches, interpreted the data, and prepared the manuscript. All authors contributed to and approved the final manuscript and reviewed it critically for important intellectual content.

\section{FUNDING}

This research was funded by the following grants from the Deutsche Forschungsgemeinschaft (DFG): Klinische Forschergruppe (KFO) 241 and PsyCourse to PF (FA241/16-1). Furthermore, funding was received from the Else KrönerFresenius Foundation within the residency/Ph.D. program “Translational Psychiatry."

\section{ACKNOWLEDGMENTS}

The authors thank Jacquie Klesing, BMedSci (Hons), Boardcertified Editor in the Life Sciences (ELS), for editing assistance with the manuscript. Ms. Klesing received compensation for her work from the Ludwig Maximilian University of Munich, Germany. 


\section{REFERENCES}

Aas, M., Djurovic, S., Athanasiu, L., Steen, N. E., Agartz, I., Lorentzen, S., et al. (2012a). Serotonin transporter gene polymorphism, childhood trauma, and cognition in patients with psychotic disorders. Schizophr. Bull. 38, 15-22. doi: $10.1093 /$ schbul/sbr113

Aas, M., Haukvik, U. K., Djurovic, S., Bergmann, O., Athanasiu, L., Tesli, M. S., et al. (2013). BDNF val66met modulates the association between childhood trauma, cognitive and brain abnormalities in psychoses. Prog. Neuropsychopharmacol. Biol. Psychiatry 46, 181-188. doi: 10.1016/j.pnpbp. 2013.07.008

Aas, M., Haukvik, U. K., Djurovic, S., Tesli, M., Athanasiu, L., Bjella, T., et al. (2014). Interplay between childhood trauma and BDNF val66met variants on blood BDNF mRNA levels and on hippocampus subfields volumes in schizophrenia spectrum and bipolar disorders. J. Psychiatr. Res. 59, 14-21. doi: 10.1016/j.jpsychires.2014.08.011

Aas, M., Kauppi, K., Brandt, C. L., Tesli, M., Kaufmann, T., Steen, N. E., et al. (2017). Childhood trauma is associated with increased brain responses to emotionally negative as compared with positive faces in patients with psychotic disorders. Psychol. Med. 47, 669-679. doi: 10.1017/S0033291716002762

Aas, M., Steen, N. E., Agartz, I., Aminoff, S. R., Lorentzen, S., Sundet, K., et al. (2012b). Is cognitive impairment following early life stress in severe mental disorders based on specific or general cognitive functioning? Psychiatry Res. 198, 495-500. doi: 10.1016/j.psychres.2011.12.045

Adriano, F., Caltagirone, C., and Spalletta, G. (2012). Hippocampal volume reduction in first-episode and chronic schizophrenia: a review and metaanalysis. Neuroscientist 18, 180-200. doi: 10.1177/1073858410395147

Agnew-Blais, J., and Danese, A. (2016). Childhood maltreatment and unfavourable clinical outcomes in bipolar disorder: a systematic review and meta-analysis. Lancet Psychiatry 3, 342-349. doi: 10.1016/S2215-0366(15)00544-1

Ahmed-Leitao, F., Spies, G., van den Heuvel, L., and Seedat, S. (2016). Hippocampal and amygdala volumes in adults with posttraumatic stress disorder secondary to childhood abuse or maltreatment: a systematic review. Psychiatry Res. Neuroimaging 256, 33-43. doi: 10.1016/j.pscychresns.2016. 09.008

Ajnakina, O., Trotta, A., Forti, M. D., Stilo, S. A., Kolliakou, A., Gardner-Sood, P., et al. (2018). Different types of childhood adversity and 5-year outcomes in a longitudinal cohort of first-episode psychosis patients. Psychiatry Res. 269, 199-206. doi: 10.1016/j.psychres.2018.08.054

Alameda, L., Ferrari, C., Baumann, P. S., Gholam-Rezaee, M., Do, K. Q., and Conus, P. (2015). Childhood sexual and physical abuse: age at exposure modulates impact on functional outcome in early psychosis patients. Psychol. Med. 45, 2727-2736. doi: 10.1017/S0033291715000690

Alameda, L., Golay, P., Baumann, P. S., Progin, P., Mebdouhi, N., Elowe, J., et al. (2017). Mild depressive symptoms mediate the impact of childhood trauma on long-term functional outcome in early psychosis patients. Schizophr. Bull. 43, 1027-1035. doi: 10.1093/schbul/sbw163

Amminger, G. P., Schafer, M. R., Schlogelhofer, M., Klier, C. M., and McGorry, P. D. (2015). Longer-term outcome in the prevention of psychotic disorders by the Vienna omega-3 study. Nat. Commun. 6:7934. doi: 10.1038/ncomms8934

Andreasen, N. C., Carpenter, WT Jr, Kane, J. M., Lasser, R. A., Marder, S. R., and Weinberger, D. R. (2005). Remission in schizophrenia: proposed criteria and rationale for consensus. Am. J. Psychiatry 162, 441-449. doi: 10.1176/appi.ajp. 162.3.441

Appiah-Kusi, E., Fisher, H. L., Petros, N., Wilson, R., Mondelli, V., Garety, P. A., et al. (2017). Do cognitive schema mediate the association between childhood trauma and being at ultra-high risk for psychosis? J. Psychiatr. Res. 88, 89-96. doi: 10.1016/j.jpsychires.2017.01.003

Arango, C., Kirkpatrick, B., and Koenig, J. (2001). At issue: stress, hippocampal neuronal turnover, and neuropsychiatric disorders. Schizophr. Bull. 27, 477-480. doi: 10.1093/oxfordjournals.schbul.a006888

Aydin, O., Balikci, K., Tas, C., Aydin, P. U., Danaci, A. E., Brune, M., et al. (2016). The developmental origins of metacognitive deficits in schizophrenia. Psychiatry Res. 245, 15-21. doi: 10.1016/j.psychres.2016.08.012

Bahari-Javan, S., Varbanov, H., Halder, R., Benito, E., Kaurani, L., Burkhardt, S., et al. (2017). HDAC1 links early life stress to schizophrenia-like phenotypes. Proc. Natl. Acad. Sci. U.S.A. 114, E4686-E4694. doi: 10.1073/pnas.1613842114
Bandelow, B., Baldwin, D., Abelli, M., Bolea-Alamanac, B., Bourin, M., Chamberlain, S. R., et al. (2017). Biological markers for anxiety disorders, OCD and PTSD: a consensus statement. Part II: Neurochemistry, neurophysiology and neurocognition. World J. Biol. Psychiatry 18, 162-214. doi: 10.1080/ 15622975.2016.1190867

Benes, F. M., Lim, B., Matzilevich, D., Walsh, J. P., Subburaju, S., and Minns, M. (2007). Regulation of the GABA cell phenotype in hippocampus of schizophrenics and bipolars. Proc. Natl. Acad. Sci. U.S.A. 104, 10164-10169. doi: 10.1073/pnas.0703806104

Berger, S. M., and Bartsch, D. (2014). The role of L-type voltage-gated calcium channels Cav1.2 and Cav1.3 in normal and pathological brain function. Cell Tissue Res. 357, 463-476. doi: 10.1007/s00441-014-1936-3

Bernstein, D. P., Ahluvalia, T., Pogge, D., and Handelsman, L. (1997). Validity of the childhood trauma questionnaire in an adolescent psychiatric population. J. Am. Acad. Child Adolesc. Psychiatry 36, 340-348. doi: 10.1097/00004583199703000-00012

Berthelot, N., Paccalet, T., Gilbert, E., Moreau, I., Merette, C., Gingras, N., et al. (2015). Childhood abuse and neglect may induce deficits in cognitive precursors of psychosis in high-risk children. J. Psychiatry Neurosci. 40, 336-343. doi: 10.1503/jpn.140211

Binbay, T., Drukker, M., Elbi, H., Tanik, F. A., Ozkinay, F., Onay, H., et al. (2012). Testing the psychosis continuum: differential impact of genetic and nongenetic risk factors and comorbid psychopathology across the entire spectrum of psychosis. Schizophr. Bull. 38, 992-1002. doi: 10.1093/schbul/sbr003

Binder, E. B., Bradley, R. G., Liu, W., Epstein, M. P., Deveau, T. C., Mercer, K. B., et al. (2008). Association of FKBP5 polymorphisms and childhood abuse with risk of posttraumatic stress disorder symptoms in adults. JAMA 299, 1291-1305. doi: 10.1001/jama.299.11.1291

Bonoldi, I., Simeone, E., Rocchetti, M., Codjoe, L., Rossi, G., Gambi, F., et al. (2013). Prevalence of self-reported childhood abuse in psychosis: a meta-analysis of retrospective studies. Psychiatry Res. 210, 8-15. doi: 10.1016/j.psychres.2013. 05.003

Bremne, J. D., and Vermetten, E. (2001). Stress and development: behavioral and biological consequences. Dev. Psychopathol. 13, 473-489. doi: 10.1017/S0954579401003042

Bremner, J. D., Bolus, R., and Mayer, E. A. (2007). Psychometric properties of the early trauma inventory-self report. J. Nerv. Ment. Dis. 195, 211-218. doi: 10.1097/01.nmd.0000243824.84651.6c

Bremner, J. D., Vermetten, E., and Mazure, C. M. (2000). Development and preliminary psychometric properties of an instrument for the measurement of childhood trauma: the Early Trauma Inventory. Depress. Anxiety 12, 1-12. doi: 10.1002/1520-6394(2000)12:1<1::AID-DA1>3.0.CO;2-W

Bzdok, D., Krzywinski, M., and Altman, N. (2018). Machine learning: supervised methods. Nat. Methods 15, 5-6. doi: 10.1038/nmeth.4551

Cancel, A., Comte, M., Boutet, C., Schneider, F. C., Rousseau, P. F., Boukezzi, S., et al. (2017). Childhood trauma and emotional processing circuits in schizophrenia: a functional connectivity study. Schizophr. Res. 184, 69-72. doi: 10.1016/j.schres.2016.12.003

Cancel, A., Comte, M., Truillet, R., Boukezzi, S., Rousseau, P. F., Zendjidjian, X. Y., et al. (2015). Childhood neglect predicts disorganization in schizophrenia through grey matter decrease in dorsolateral prefrontal cortex. Acta Psychiatr. Scand. 132, 244-256. doi: 10.1111/acps.12455

Carol, E. E., and Mittal, V. A. (2015). Resting cortisol level, self-concept, and putative familial environment in adolescents at ultra high-risk for psychotic disorders. Psychoneuroendocrinology 57, 26-36. doi: 10.1016/j.psyneuen.2015. 03.018

Cascio, M. T., Cella, M., Preti, A., Meneghelli, A., and Cocchi, A. (2012). Gender and duration of untreated psychosis: a systematic review and meta-analysis. Early Interv. Psychiatry 6, 115-127. doi: 10.1111/j.1751-7893.2012.00351.x

Cassoli, J. S., Guest, P. C., Malchow, B., Schmitt, A., Falkai, P., and Martinsde-Souza, D. (2015). Disturbed macro-connectivity in schizophrenia linked to oligodendrocyte dysfunction: from structural findings to molecules. NPJ Schizophr. 1:15034. doi: 10.1038/npjschz.2015.34

Castro-Vale, I., van Rossum, E. F., Machado, J. C., Mota-Cardoso, R., and Carvalho, D. (2016). Genetics of glucocorticoid regulation and posttraumatic stress disorder-What do we know? Neurosci. Biobehav. Rev. 63, 143-157. doi: 10.1016/j.neubiorev.2016.02.005 
Chan, R. C. H., Mak, W. W. S., Chio, F. H. N., and Tong, A. C. Y. (2018). Flourishing with psychosis: a prospective examination on the interactions between clinical, functional, and personal recovery processes on well-being among individuals with schizophrenia spectrum disorders. Schizophr. Bull. 44, 778-786. doi: 10.1093/schbul/sbx120

Chandler, L. A. (1981). The source of stress inventory. Psychol. Sch. 18, 164-168. doi: 10.1002/1520-6807(198104)18:2<164::AID-PITS2310180209>3.0.CO;2-C

Chen, D., Meng, L., Pei, F., Zheng, Y., and Leng, J. (2017). A review of DNA methylation in depression. J. Clin. Neurosci. 43, 39-46. doi: 10.1016/j.jocn.2017. 05.022

Choi, K. W., and Sikkema, K. J. (2016). Childhood maltreatment and perinatal mood and anxiety disorders: a systematic review. Trauma Violence Abuse 17, 427-453. doi: 10.1177/1524838015584369

Ciufolini, S., Dazzan, P., Kempton, M. J., Pariante, C., and Mondelli, V. (2014). HPA axis response to social stress is attenuated in schizophrenia but normal in depression: evidence from a meta-analysis of existing studies. Neurosci. Biobehav. Rev. 47, 359-368. doi: 10.1016/j.neubiorev.2014.09.004

Corcoran, C., Walker, E., Huot, R., Mittal, V., Tessner, K., Kestler, L., et al. (2003). The stress cascade and schizophrenia: etiology and onset. Schizophr. Bull. 29, 671-692. doi: 10.1093/oxfordjournals.schbul.a007038

Crossfield, A. G., Alloy, L. B., Gibb, B. E., and Abramson, L. Y. (2002). The development of depressogenic cognitive styles: the role of negative childhood life events and parental inferential feedback. J. Cogn. Psychother. 16, 487-502. doi: 10.1891/jcop.16.4.487.52530

Damsted, S. K., Born, A. P., Paulson, O. B., and Uldall, P. (2011). Exogenous glucocorticoids and adverse cerebral effects in children. Eur. J. Paediatr. Neurol. 15, 465-477. doi: 10.1016/j.ejpn.2011.05.002

Daruy-Filho, L., Brietzke, E., Lafer, B., and Grassi-Oliveira, R. (2011). Childhood maltreatment and clinical outcomes of bipolar disorder. Acta Psychiatr. Scand. 124, 427-434. doi: 10.1111/j.1600-0447.2011.01756.x

Davis, J., Eyre, H., Jacka, F. N., Dodd, S., Dean, O., McEwen, S., et al. (2016). A review of vulnerability and risks for schizophrenia: beyond the two hit hypothesis. Neurosci. Biobehav. Rev. 65, 185-194. doi: 10.1016/j.neubiorev. 2016.03.017

Docherty, N. M., St-Hilaire, A., Aakre, J. M., and Seghers, J. P. (2009). Life events and high-trait reactivity together predict psychotic symptom increases in schizophrenia. Schizophr. Bull. 35, 638-645. doi: 10.1093/schbul/sbn002

Dwyer, D. B., Cabral, C., Kambeitz-Ilankovic, L., Sanfelici, R., Kambeitz, J., Calhoun, V., et al. (2018a). Brain subtyping enhances the neuroanatomical discrimination of schizophrenia. Schizophr. Bull. 44, 1060-1069. doi: 10.1093/ schbul/sby008

Dwyer, D. B., Falkai, P., and Koutsouleris, N. (2018b). Machine learning approaches for clinical psychology and psychiatry. Annu. Rev. Clin. Psychol. 14, 91-118. doi: 10.1146/annurev-clinpsy-032816-045037

Falkai, P., Schmitt, A., and Cannon, T. D. (2011). "Pathophysiology of schizophrenia," in Schizophrenia: Current Science and Clinical Practice, ed. W. Gaebel (Hoboken, NJ: Wiley-Blackwell), 31-65. doi: 10.1002/97804709 78672.ch2

Fatemi, S. H., and Folsom, T. D. (2009). The neurodevelopmental hypothesis of schizophrenia, revisited. Schizophr. Bull. 35, 528-548. doi: 10.1093/schbul/ sbn 187

Felitti, V. J., Anda, R. F., Nordenberg, D., Williamson, D. F., Spitz, A. M., Edwards, V., et al. (1998). Relationship of childhood abuse and household dysfunction to many of the leading causes of death in adults. The Adverse Childhood Experiences (ACE) Study. Am. J. Prev. Med. 14, 245-258. doi: 10. 1016/S0749-3797(98)00017-8

Fischer, A. (2014). Epigenetic memory: the Lamarckian brain. EMBO J. 33, 945967. doi: 10.1002/embj.201387637

Franklin, C. L., Raines, A. M., Cuccurullo, L. J., Chambliss, J. L., Maieritsch, K. P., Tompkins, A. M., et al. (2018). 27 ways to meet PTSD: Using the PTSD-checklist for DSM-5 to examine PTSD core criteria. Psychiatry Res. 261, 504-507. doi: 10.1016/j.psychres.2018.01.021

Frodl, T., and O'Keane, V. (2013). How does the brain deal with cumulative stress? A review with focus on developmental stress, HPA axis function and hippocampal structure in humans. Neurobiol. Dis. 52, 24-37. doi: 10.1016/j.nbd. 2012.03.012

Galatzer-Levy, I. R., Karstoft, K. I., Statnikov, A., and Shalev, A. Y. (2014). Quantitative forecasting of PTSD from early trauma responses: a machine learning application. J. Psychiatr. Res. 59, 68-76. doi: 10.1016/j.jpsychires.2014. 08.017

Grandin, L. D., Alloy, L. B., and Abramson, L. Y. (2007). Childhood stressful life events and bipolar spectrum disorders. J. Soc. Clin. Psychol. 26, 460-478. doi: $10.1521 /$ jscp.2007.26.4.460

Green, K., Browne, K., and Chou, S. (2017). The relationship between childhood maltreatment and violence to others in individuals with psychosis: a systematic review and meta-analysis. Trauma Violence Abuse doi: 10.1177/ 1524838017708786 [Epub ahead of print].

Green, M. F. (1996). What are the functional consequences of neurocognitive deficits in schizophrenia? Am. J. Psychiatry 153, 321-330. doi: 10.1176/ajp.153. 3.321

Green, M. F., Horan, W. P., and Lee, J. (2015a). Social cognition in schizophrenia. Nat. Rev. Neurosci. 16, 620-631. doi: 10.1038/nrn4005

Green, M. J., Raudino, A., Cairns, M. J., Wu, J., Tooney, P. A., Scott, R. J., et al. (2015b). Do common genotypes of FK506 binding protein 5 (FKBP5) moderate the effects of childhood maltreatment on cognition in schizophrenia and healthy controls? J. Psychiatr. Res. 70, 9-17. doi: 10.1016/j.jpsychires.2015. 07.019

Green, M. J., Chia, T. Y., Cairns, M. J., Wu, J., Tooney, P. A., Scott, R. J., et al. (2014). Catechol-O-methyltransferase (COMT) genotype moderates the effects of childhood trauma on cognition and symptoms in schizophrenia. J. Psychiatr. Res. 49, 43-50. doi: 10.1016/j.jpsychires.2013.10.018

Guina, J., Welton, R. S., Broderick, P. J., Correll, T. L., and Peirson, R. P. (2016). DSM-5 criteria and its implications for diagnosing PTSD in military service members and veterans. Curr. Psychiatry Rep. 18:43. doi: 10.1007/s11920-0160686-1

Gur, R. E., and Gur, R. C. (2016). Sex differences in brain and behavior in adolescence: findings from the Philadelphia neurodevelopmental cohort. Neurosci. Biobehav. Rev. 70, 159-170. doi: 10.1016/j.neubiorev.2016. 07.035

Gustavsson, A., Svensson, M., Jacobi, F., Allgulander, C., Alonso, J., Beghi, E., et al. (2011). Cost of disorders of the brain in Europe 2010. Eur. Neuropsychopharmacol. 21, 718-779. doi: 10.1016/j.euroneuro.2011.08.008

Häfner, H., and an der Heiden, W. (2007). "Course and outcome of Schizophrenia," in Schizophrenia, 2nd Edn, eds S. R. Hirsch and D. R. Weinberger (Hoboken, NJ: Wiely), 101-104.

Heim, C., Bradley, B., Mletzko, T. C., Deveau, T. C., Musselman, D. L., Nemeroff, C. B., et al. (2009). Effect of childhood trauma on adult depression and neuroendocrine function: sex-specific moderation by CRH receptor 1 gene. Front. Behav. Neurosci. 3:41. doi: 10.3389/neuro.08.041.2009

Hoff, A. L., Svetina, C., Shields, G., Stewart, J., and DeLisi, L. E. (2005). Ten year longitudinal study of neuropsychological functioning subsequent to a first episode of schizophrenia. Schizophr. Res. 78, 27-34. doi: 10.1016/j.schres.2005. 05.010

Holtzman, C. W., Trotman, H. D., Goulding, S. M., Ryan, A. T., Macdonald, A. N., Shapiro, D. I., et al. (2013). Stress and neurodevelopmental processes in the emergence of psychosis. Neuroscience 249, 172-191. doi: 10.1016/j. neuroscience.2012.12.017

Hovdestad, W., Campeau, A., Potter, D., and Tonmyr, L. (2015). A systematic review of childhood maltreatment assessments in population-representative surveys since 1990. PLoS One 10:e0123366. doi: 10.1371/journal.pone.0123366

Infurna, M. R., Reichl, C., Parzer, P., Schimmenti, A., Bifulco, A., and Kaess, M. (2016). Associations between depression and specific childhood experiences of abuse and neglect: a meta-analysis. J. Affect. Disord. 190, 47-55. doi: 10.1016/j. jad.2015.09.006

Isvoranu, A. M., van Borkulo, C. D., Boyette, L. L., Wigman, J. T., Vinkers, C. H., Borsboom, D., et al. (2017). A network approach to psychosis: pathways between childhood trauma and psychotic symptoms. Schizophr. Bull. 43, 187196. doi: $10.1093 /$ schbul/sbw055

Jablensky, A. (1995). Schizophrenia: recent epidemiologic issues. Epidemiol. Rev. 17, 10-20. doi: 10.1093/oxfordjournals.epirev.a036164

Jagannath, V., Gerstenberg, M., Walitza, S., Franscini, M., Heekeren, K., Rossler, W., et al. (2018). Neuregulin 1 (NRG1) gene expression predicts functional outcomes in individuals at clinical high-risk for psychosis. Psychiatry Res. 266, 143-146. doi: 10.1016/j.psychres.2018.05.025

Jeppesen, P., Larsen, J. T., Clemmensen, L., Munkholm, A., Rimvall, M. K., Rask, C. U., et al. (2015). The CCC2000 birth cohort study of register-based family 
history of mental disorders and psychotic experiences in offspring. Schizophr. Bull. 41, 1084-1094. doi: 10.1093/schbul/sbu167

Jessen, K., Mandl, R. C. W., Fagerlund, B., Bojesen, K. B., Raghava, J. M., Obaid, H. G., et al. (2018). Patterns of cortical structures and cognition in antipsychotic-naive patients with first-episode schizophrenia: a partial least squares correlation analysis. Biol. Psychiatry Cogn. Neurosci. Neuroimaging. doi: 10.1016/j.bpsc.2018.09.006 [Epub ahead of print].

Jollans, L., and Whelan, R. (2018). Neuromarkers for mental disorders: harnessing population neuroscience. Front. Psychiatry 9:242. doi: 10.3389/fpsyt.2018.00242

Jones, S. R., and Fernyhough, C. (2007). A new look at the neural diathesis-stress model of schizophrenia: the primacy of social-evaluative and uncontrollable situations. Schizophr. Bull. 33, 1171-1177. doi: 10.1093/schbul/sbl058

Kane, J. M., Borenstein, M., and Woerner, M. (1984). Psychopharmacologic issues in the maintenance treatment of schizophrenia. Psychopharmacol. Bull. 20, 423-425.

Karstoft, K. I., Galatzer-Levy, I. R., Statnikov, A., Li, Z., Shalev, A. Y., and For members of the Jerusalem Trauma Outreach and Prevention Study (J-Tops) group (2015). Bridging a translational gap: using machine learning to improve the prediction of PTSD. BMC Psychiatry 15:30. doi: 10.1186/s12888-015-0399-8

Kelly, D. L., Rowland, L. M., Patchan, K. M., Sullivan, K., Earl, A., Raley, H., et al. (2016). Schizophrenia clinical symptom differences in women vs. men with and without a history of childhood physical abuse. Child Adolesc. Psychiatry Ment. Health 10:5. doi: 10.1186/s13034-016-0092-9

Kessler, R. C., Angermeyer, M., Anthony, J. C., De Graaf, R., Demyttenaere, K., Gasquet, I., et al. (2007). Lifetime prevalence and age-of-onset distributions of mental disorders in the World Health Organization's World Mental Health Survey Initiative. World Psychiatry 6, 168-176.

Kilian, S., Burns, J. K., Seedat, S., Asmal, L., Chiliza, B., Du Plessis, S., et al. (2017). Factors moderating the relationship between childhood trauma and premorbid adjustment in first-episode schizophrenia. PLoS One 12:e0170178. doi: 10.1371 /journal.pone. 0170178

Koss, M. P., Gidycz, C. A., and Wisniewski, N. (1987). The scope of rape: incidence and prevalence of sexual aggression and victimization in a national sample of higher education students. J. Consult. Clin. Psychol. 55, 162-170. doi: 10.1037/ 0022-006X.55.2.162

Koutsouleris, N., Kahn, R. S., Chekroud, A. M., Leucht, S., Falkai, P., Wobrock, T., et al. (2016). Multisite prediction of 4-week and 52-week treatment outcomes in patients with first-episode psychosis: a machine learning approach. Lancet Psychiatry 3, 935-946. doi: 10.1016/S2215-0366(16)30171-7

Kraan, T., van Dam, D. S., Velthorst, E., de Ruigh, E. L., Nieman, D. H., Durston, S., et al. (2015). Childhood trauma and clinical outcome in patients at ultra-high risk of transition to psychosis. Schizophr. Res. 169, 193-198. doi: 10.1016/j. schres.2015.10.030

Krakauer, K., Ebdrup, B. H., Glenthoj, B. Y., Raghava, J. M., Nordholm, D., Randers, L., et al. (2017). Patterns of white matter microstructure in individuals at ultra-high-risk for psychosis: associations to level of functioning and clinical symptoms. Psychol. Med. 47, 2689-2707. doi: 10.1017/S0033291717 001210

Kubany, E. S., Haynes, S. N., Leisen, M. B., Owens, J. A., Kaplan, A. S., Watson, S. B., et al. (2000). Development and preliminary validation of a brief broad-spectrum measure of trauma exposure: the Traumatic Life Events Questionnaire. Psychol. Assess. 12, 210-224. doi: 10.1037/1040-3590.12.2.210

Larsson, S., Andreassen, O. A., Aas, M., Rossberg, J. I., Mork, E., Steen, N. E., et al. (2013). High prevalence of childhood trauma in patients with schizophrenia spectrum and affective disorder. Compr. Psychiatry 54, 123-127. doi: 10.1016/j. comppsych.2012.06.009

Lho, S. K., Kim, M., Lee, T. H., Kwak, Y. B., and Kwon, J. S. (2019). Predicting prognosis in patients with first-episode psychosis using auditory P300: a 1year follow-up study. Clin. Neurophysiol. 130, 46-54. doi: 10.1016/j.clinph.2018. 10.011

Li, X. B., Bo, Q. J., Zhang, G. P., Zheng, W., Wang, Z. M., Li, A. N., et al. (2017). Effect of childhood trauma on cognitive functions in a sample of Chinese patients with schizophrenia. Compr. Psychiatry 76, 147-152. doi: 10.1016/j. comppsych.2017.04.010

MacDonald, K., Thomas, M. L., MacDonald, T. M., and Sciolla, A. F. (2015). A perfect childhood? Clinical correlates of minimization and denial on the childhood trauma questionnaire. J. Interpers. Violence 30, 988-1009. doi: 10. $1177 / 0886260514539761$
Magarinos, A. M., Li, C. J., Gal Toth, J., Bath, K. G., Jing, D., Lee, F. S., et al. (2011). Effect of brain-derived neurotrophic factor haploinsufficiency on stress-induced remodeling of hippocampal neurons. Hippocampus 21, 253-264. doi: 10.1002/hipo.20744

Makinodan, M., Rosen, K. M., Ito, S., and Corfas, G. (2012). A critical period for social experience-dependent oligodendrocyte maturation and myelination. Science 337, 1357-1360. doi: 10.1126/science. 1220845

Malarbi, S., Abu-Rayya, H. M., Muscara, F., and Stargatt, R. (2017). Neuropsychological functioning of childhood trauma and post-traumatic stress disorder: a meta-analysis. Neurosci. Biobehav. Rev. 72, 68-86. doi: 10.1016/j.neubiorev.2016.11.004

Mandelli, L., Petrelli, C., and Serretti, A. (2015). The role of specific early trauma in adult depression: a meta-analysis of published literature. Childhood trauma and adult depression. Eur. Psychiatry 30, 665-680. doi: 10.1016/j.eurpsy.2015.04.007

Manolio, T. A., Collins, F. S., Cox, N. J., Goldstein, D. B., Hindorff, L. A., Hunter, D. J., et al. (2009). Finding the missing heritability of complex diseases. Nature 461, 747-753. doi: $10.1038 /$ nature 08494

McGrath, J., Saha, S., Chant, D., and Welham, J. (2008). Schizophrenia: a concise overview of incidence, prevalence, and mortality. Epidemiol. Rev. 30, 67-76. doi: 10.1093/epirev/mxn001

Misiak, B., Szmida, E., Karpinski, P., Loska, O., Sasiadek, M. M., and Frydecka, D. (2015). Lower LINE-1 methylation in first-episode schizophrenia patients with the history of childhood trauma. Epigenomics 7, 1275-1285. doi: 10.2217/epi. 15.68

Mondelli, V., Pariante, C. M., Navari, S., Aas, M., D’Albenzio, A., Di Forti, M., et al. (2010). Higher cortisol levels are associated with smaller left hippocampal volume in first-episode psychosis. Schizophr. Res. 119, 75-78. doi: 10.1016/j. schres.2009.12.021

Morgan, C., and Fisher, H. (2007). Environment and schizophrenia: environmental factors in schizophrenia: childhood trauma-a critical review. Schizophr. Bull. 33, 3-10. doi: 10.1093/schbul/sbl053

Murray, C. J., and Lopez, A. D. (1996). Evidence-based health policy-lessons from the global burden of disease study. Science 274, 740-743. doi: 10.1126/science. 274.5288.740

Nestler, E. J., Pena, C. J., Kundakovic, M., Mitchell, A., and Akbarian, S. (2016). Epigenetic basis of mental illness. Neuroscientist 22, 447-463. doi: 10.1177/ 1073858415608147

Neto, F. L., Borges, G., Torres-Sanchez, S., Mico, J. A., and Berrocoso, E. (2011). Neurotrophins role in depression neurobiology: a review of basic and clinical evidence. Curr. Neuropharmacol. 9, 530-552. doi: 10.2174/ 157015911798376262

Nordholm, D., Rostrup, E., Mondelli, V., Randers, L., Nielsen, M. O., Wulff, S., et al. (2018). Multiple measures of HPA axis function in ultra high risk and first-episode schizophrenia patients. Psychoneuroendocrinology 92, 72-80. doi: 10.1016/j.psyneuen.2018.03.015

Orphanou, K., Stassopoulou, A., and Keravnou, E. (2014). Temporal abstraction and temporal Bayesian networks in clinical domains: a survey. Artif. Intell. Med. 60, 133-149. doi: 10.1016/j.artmed.2013.12.007

Pardinas, A. F., Holmans, P., Pocklington, A. J., Escott-Price, V., Ripke, S., Carrera, N., et al. (2018). Common schizophrenia alleles are enriched in mutation-intolerant genes and in regions under strong background selection. Nat. Genet. 50, 381-389. doi: 10.1038/s41588-018-0059-2

Plaza, A., Garcia-Esteve, L., Torres, A., Ascaso, C., Gelabert, E., Luisa Imaz, M., et al. (2012). Childhood physical abuse as a common risk factor for depression and thyroid dysfunction in the earlier postpartum. Psychiatry Res. 200, 329-335. doi: 10.1016/j.psychres.2012.06.032

Plaza, A., Torres, A., Martin-Santos, R., Gelabert, E., Imaz, M. L., Navarro, P., et al. (2011). Validation and test-retest reliability of early trauma inventory in Spanish postpartum women. J. Nerv. Ment. Dis. 199, 280-285. doi: 10.1097/ NMD.0b013e31821245b9

Pries, L. K., Guloksuz, S., Ten Have, M., de Graaf, R., van Dorsselaer, S., Gunther, N., et al. (2018). Evidence that environmental and familial risks for psychosis additively impact a multidimensional subthreshold psychosis syndrome. Schizophr. Bull. 44, 710-719. doi: 10.1093/schbul/sby051

Quide, Y., O’Reilly, N., Rowland, J. E., Carr, V. J., Elzinga, B. M., and Green, M. J. (2017a). Effects of childhood trauma on working memory in affective and non-affective psychotic disorders. Brain Imaging Behav. 11, 722-735. doi: $10.1007 / \mathrm{s} 11682-016-9548-\mathrm{z}$ 
Quide, Y., Ong, X. H., Mohnke, S., Schnell, K., Walter, H., Carr, V. J., et al. (2017b). Childhood trauma-related alterations in brain function during a Theory-ofMind task in schizophrenia. Schizophr. Res. 189, 162-168. doi: 10.1016/j.schres. 2017.02.012

Radhakrishnan, R., Guloksuz, S., Ten Have, M., de Graaf, R., van Dorsselaer, S., Gunther, N., et al. (2018). Interaction between environmental and familial affective risk impacts psychosis admixture in states of affective dysregulation. Psychol. Med. doi: 10.1017/S0033291718002635 [Epub ahead of print].

Ramo-Fernandez, L., Schneider, A., Wilker, S., and Kolassa, I. T. (2015). Epigenetic alterations associated with war trauma and childhood maltreatment. Behav. Sci. Law 33, 701-721. doi: 10.1002/bsl.2200

Rampp, C., Binder, E. B., and Provencal, N. (2014). Epigenetics in posttraumatic stress disorder. Prog. Mol. Biol. Transl. Sci. 128, 29-50. doi: 10.1016/B978-012-800977-2.00002-4

Ressler, K. J., Bradley, B., Mercer, K. B., Deveau, T. C., Smith, A. K., Gillespie, C. F., et al. (2010). Polymorphisms in CRHR1 and the serotonin transporter loci: gene $\mathrm{x}$ gene $\mathrm{x}$ environment interactions on depressive symptoms. Am. J. Med. Genet. B Neuropsychiatr. Genet. 153B, 812-824. doi: 10.1002/ajmg.b.31052

Rich-Edwards, J. W., James-Todd, T., Mohllajee, A., Kleinman, K., Burke, A., Gillman, M. W., et al. (2011). Lifetime maternal experiences of abuse and risk of pre-natal depression in two demographically distinct populations in Boston. Int. J. Epidemiol. 40, 375-384. doi: 10.1093/ije/dyq247

Riglin, L., Collishaw, S., Richards, A., Thapar, A. K., Maughan, B., O’Donovan, M. C., et al. (2017). Schizophrenia risk alleles and neurodevelopmental outcomes in childhood: a population-based cohort study. Lancet Psychiatry 4, 57-62. doi: 10.1016/S2215-0366(16)30406-0

Ripke, S., O’Dushlaine, C., Chambert, K., Moran, J. L., Kahler, A. K., Akterin, S., et al. (2013). Genome-wide association analysis identifies 13 new risk loci for schizophrenia. Nat. Genet. 45, 1150-1159. doi: 10.1038/ng.2742

Ryali, S., Supekar, K., Chen, T., Kochalka, J., Cai, W., Nicholas, J., et al. (2016). Temporal dynamics and developmental maturation of salience, default and central-executive network interactions revealed by variational bayes hidden markov modeling. PLoS Comput. Biol. 12:e1005138. doi: 10.1371/journal.pcbi. 1005138

Ryan, M. C., Sharifi, N., Condren, R., and Thakore, J. H. (2004). Evidence of basal pituitary-adrenal overactivity in first episode, drug naive patients with schizophrenia. Psychoneuroendocrinology 29, 1065-1070. doi: 10.1016/j. psyneuen.2003.08.011

Sahu, G., Malavade, K., and Jacob, T. (2016). Cognitive impairment in schizophrenia: interplay of BDNF and childhood trauma? A review of literature. Psychiatr. Q. 87, 559-569. doi: 10.1007/s11126-015-9409-8

Sapolsky, R. M., Uno, H., Rebert, C. S., and Finch, C. E. (1990). Hippocampal damage associated with prolonged glucocorticoid exposure in primates. J. Neurosci. 10, 2897-2902. doi: 10.1523/JNEUROSCI.10-09-02897.1990

Schennach, R., Riedel, M., Obermeier, M., Spellmann, I., Musil, R., Jager, M., et al. (2015). What are residual symptoms in schizophrenia spectrum disorder? Clinical description and 1-year persistence within a naturalistic trial. Eur. Arch. Psychiatry Clin. Neurosci. 265, 107-116. doi: 10.1007/s00406-014-0528-2

Schmitt, A., Malchow, B., Hasan, A., and Falkai, P. (2014). The impact of environmental factors in severe psychiatric disorders. Front. Neurosci. 8:19. doi: 10.3389/fnins.2014.00019

Scott, J., Leboyer, M., Hickie, I., Berk, M., Kapczinski, F., Frank, E., et al. (2013). Clinical staging in psychiatry: a cross-cutting model of diagnosis with heuristic and practical value. Br. J. Psychiatry 202, 243-245. doi: 10.1192/bjp.bp.112. 110858

Seltman, H. J., Mitchell, S., and Sweet, R. A. (2016). A Bayesian model of psychosis symptom trajectory in Alzheimer's disease. Int. J. Geriatr. Psychiatry 31, 204210. doi: 10.1002 /gps.4326

Shannon, C., Douse, K., McCusker, C., Feeney, L., Barrett, S., and Mulholland, C. (2011). The association between childhood trauma and memory functioning in schizophrenia. Schizophr. Bull. 37, 531-537. doi: 10.1093/schbul/sbp096

Sharma, R. P., Grayson, D. R., and Gavin, D. P. (2008). Histone deactylase 1 expression is increased in the prefrontal cortex of schizophrenia subjects: analysis of the National Brain Databank microarray collection. Schizophr. Res. 98, 111-117. doi: 10.1016/j.schres.2007.09.020

Smeets, F., Lataster, T., Viechtbauer, W., Delespaul, P., and G.R.O.U.P (2015). Evidence that environmental and genetic risks for psychotic disorder may operate by impacting on connections between core symptoms of perceptual alteration and delusional ideation. Schizophr. Bull. 41, 687-697. doi: 10.1093/ schbul/sbu122

Stein, D. J., McLaughlin, K. A., Koenen, K. C., Atwoli, L., Friedman, M. J., Hill, E. D., et al. (2014). DSM-5 and ICD-11 definitions of posttraumatic stress disorder: investigating "narrow" and "broad" approaches. Depress. Anxiety 31, 494-505. doi: 10.1002/da.22279

Stein-O’Brien, G. L., Arora, R., Culhane, A. C., Favorov, A. V., Garmire, L. X., Greene, C. S., et al. (2018). Enter the matrix: factorization uncovers knowledge from Omics. Trends Genet. 34, 790-805. doi: 10.1016/j.tig.2018.07.003

Straus, M. A., and Douglas, E. M. (2004). A short form of the revised conflict tactics scales, and typologies for severity and mutuality. Violence Vict. 19, 507-520. doi: 10.1891/vivi.19.5.507.63686

Sullivan, P. F., Kendler, K. S., and Neale, M. C. (2003). Schizophrenia as a complex trait: evidence from a meta-analysis of twin studies. Arch. Gen. Psychiatry 60, 1187-1192. doi: 10.1001/archpsyc.60.12.1187

Teicher, M. H., and Samson, J. A. (2013). Childhood maltreatment and psychopathology: a case for ecophenotypic variants as clinically and neurobiologically distinct subtypes. Am. J. Psychiatry 170, 1114-1133. doi: 10.1176/appi.ajp.2013.12070957

Tomassi, S., and Tosato, S. (2017). Epigenetics and gene expression profile in firstepisode psychosis: The role of childhood trauma. Neurosci. Biobehav. Rev. 83, 226-237. doi: 10.1016/j.neubiorev.2017.10.018

Trauelsen, A. M., Bendall, S., Jansen, J. E., Nielsen, H. G., Pedersen, M. B., Trier, C. H., et al. (2016). Childhood adversities: social support, premorbid functioning and social outcome in first-episode psychosis and a matched case-control group. Aust. N. Z. J. Psychiatry 50, 770-782. doi: 10.1177/ 0004867415625814

Trotta, A., Murray, R. M., David, A. S., Kolliakou, A., O’Connor, J., Di Forti, M., et al. (2016). Impact of different childhood adversities on 1-year outcomes of psychotic disorder in the genetics and psychosis study. Schizophr. Bull. 42, 464-475. doi: 10.1093/schbul/sbv131

Valli, I., Crossley, N. A., Day, F., Stone, J., Tognin, S., Mondelli, V., et al. (2016). HPA-axis function and grey matter volume reductions: imaging the diathesisstress model in individuals at ultra-high risk of psychosis. Transl. Psychiatry 6:e797. doi: 10.1038/tp.2016.68

van Venrooij, J. A., Fluitman, S. B., Lijmer, J. G., Kavelaars, A., Heijnen, C. J., Westenberg, H. G., et al. (2012). Impaired neuroendocrine and immune response to acute stress in medication-naive patients with a first episode of psychosis. Schizophr. Bull. 38, 272-279. doi: 10.1093/schbul/sbq062

van Winkel, R., Stefanis, N. C., and Myin-Germeys, I. (2008). Psychosocial stress and psychosis. A review of the neurobiological mechanisms and the evidence for gene-stress interaction. Schizophr. Bull. 34, 1095-1105. doi: 10.1093/schbul/ sbn 101

Varese, F., Smeets, F., Drukker, M., Lieverse, R., Lataster, T., Viechtbauer, W., et al. (2012). Childhood adversities increase the risk of psychosis: a meta-analysis of patient-control, prospective- and cross-sectional cohort studies. Schizophr. Bull. 38, 661-671. doi: 10.1093/schbul/sbs050

Varty, G. B., Powell, S. B., Lehmann-Masten, V., Buell, M. R., and Geyer, M. A. (2006). Isolation rearing of mice induces deficits in prepulse inhibition of the startle response. Behav. Brain Res. 169, 162-167. doi: 10.1016/j.bbr.2005.11.025

Veling, W., Counotte, J., Pot-Kolder, R., van Os, J., and van der Gaag, M. (2016). Childhood trauma, psychosis liability and social stress reactivity: a virtual reality study. Psychol. Med. 46, 3339-3348. doi: 10.1017/S0033291716002208

Viola, T. W., Salum, G. A., Kluwe-Schiavon, B., Sanvicente-Vieira, B., Levandowski, M. L., and Grassi-Oliveira, R. (2016). The influence of geographical and economic factors in estimates of childhood abuse and neglect using the childhood trauma questionnaire: a worldwide meta-regression analysis. Child Abuse Negl. 51, 1-11. doi: 10.1016/j.chiabu.2015.11.019

Walker, E., Mittal, V., and Tessner, K. (2008). Stress and the hypothalamic pituitary adrenal axis in the developmental course of schizophrenia. Annu. Rev. Clin. Psychol. 4, 189-216. doi: 10.1146/annurev.clinpsy.4.022007.141248

Walker, E. F., and Diforio, D. (1997). Schizophrenia: a neural diathesis-stress model. Psychol. Rev. 104, 667-685. doi: 10.1037/0033-295X.104.4.667

Watanabe, Y., Gould, E., Cameron, H. A., Daniels, D. C., and McEwen, B. S. (1992). Phenytoin prevents stress- and corticosterone-induced atrophy of CA3 pyramidal neurons. Hippocampus 2, 431-435. doi: 10.1002/hipo.450020410

Weathers, F. W., Bovin, M. J., Lee, D. J., Sloan, D. M., Schnurr, P. P., Kaloupek, D. G., et al. (2018). The clinician-administered PTSD Scale for 
DSM-5 (CAPS-5): development and initial psychometric evaluation in military veterans. Psychol. Assess. 30, 383-395. doi: 10.1037/pas0000486

Weathers, F. W., Keane, T. M., and Davidson, J. R. (2001). Clinician-administered PTSD scale: a review of the first ten years of research. Depress. Anxiety 13, 132-156. doi: 10.1002/da.1029

Weinberger, D. R. (1996). On the plausibility of "the neurodevelopmental hypothesis" of schizophrenia. Neuropsychopharmacology 14(3 Suppl.), 1S-11S. doi: 10.1016/0893-133X(95)00199-N

Whiteford, H. A., Degenhardt, L., Rehm, J., Baxter, A. J., Ferrari, A. J., Erskine, H. E., et al. (2013). Global burden of disease attributable to mental and substance use disorders: findings from the Global Burden of Disease Study 2010. Lancet 382, 1575-1586. doi: 10.1016/S0140-6736(13)61611-6

Yampolsky, L., Lev-Wiesel, R., and Ben-Zion, I. Z. (2010). Child sexual abuse: is it a risk factor for pregnancy? J. Adv. Nurs. 66, 2025-2037. doi: 10.1111/j.13652648.2010.05387.x

Yung, A. R., Cotter, J., Wood, S. J., McGorry, P., Thompson, A. D., Nelson, B., et al. (2015). Childhood maltreatment and transition to psychotic disorder independently predict long-term functioning in young people at ultra-high risk for psychosis. Psychol. Med. 45, 3453-3465. doi: 10.1017/S003329171500 $135 \mathrm{X}$

Zorn, J. V., Schur, R. R., Boks, M. P., Kahn, R. S., Joels, M., and Vinkers, C. H. (2017). Cortisol stress reactivity across psychiatric disorders: a systematic review and meta-analysis. Psychoneuroendocrinology 77, 25-36. doi: 10.1016/j. psyneuen.2016.11.036
Zwicker, A., Denovan-Wright, E. M., and Uher, R. (2018). Gene-environment interplay in the etiology of psychosis. Psychol. Med. 48, 1925-1936. doi: 10.1017/ S003329171700383X

Conflict of Interest Statement: PF has been an honorary speaker for AstraZeneca, Bristol Myers Squibb, Lilly, Essex, GE Healthcare, GlaxoSmithKline, Janssen Cilag, Lundbeck, Otsuka, Pfizer, Servier, and Takeda and has been a member of the advisory boards of Janssen-Cilag, AstraZeneca, Lilly, and Lundbeck. AS was honorary speaker for TAD Pharma and Roche and a member of Roche advisory boards.

The remaining authors declare that the research was conducted in the absence of any commercial or financial relationships that could be construed as a potential conflict of interest.

The handling Editor declared a past co-authorship with one of the authors PF.

Copyright (๑ 2019 Popovic, Schmitt, Kaurani, Senner, Papiol, Malchow, Fischer, Schulze, Koutsouleris and Falkai. This is an open-access article distributed under the terms of the Creative Commons Attribution License (CC BY). The use, distribution or reproduction in other forums is permitted, provided the original author(s) and the copyright owner(s) are credited and that the original publication in this journal is cited, in accordance with accepted academic practice. No use, distribution or reproduction is permitted which does not comply with these terms. 